\title{
Documentation Of Cactii From Agriculture Farm Of Dehgam Area, Gujarat
}

\author{
Harshida Chavda ${ }^{1}$, Shirin Qureshi ${ }^{2}$, Archana Mankad $^{3}$, Hitesh Solanki ${ }^{4}$ \\ ${ }^{1}$ M.Sc. Student, ${ }^{2}$ Research Scholar, ${ }^{3,4}$ Professor \\ ${ }^{1,2,3,4}$ Department Of Botany, Bioinformatics, Climate Change Impacts Management, Gujarat University, \\ Ahmedabad-9. \\ Email Id:Husolanki@Yahoo.Com
}

\begin{abstract}
Cactii are a unique group of plants that are found in its natural environment, in North and South America and South America, maximum seen in Mexico. The major characters in stem are fewer leaves, spines and fleshy wall. The areoles are special characters in the cactus which are protected by spines. Only Pereksiagenus have leaf and in other species leaves are modified into spines. The spines vary in size and colour. It is very important in identification of cactus. We visited Poonam Agriculture Farm, Ahmedabad, Gujarat in India in the year 2018-2019 for 3 months. We saw 300 species of cactus in the field and out of them, we studied 14 genus having above characters which are: Astrophytum, Copiapoa, Claistocactus, Espostoa, Echinocactus, Echinocereus, Echinopsis, Cereus, Ferocactus, Gymnocalycium, Mammillaria, Notocactus, Sulcorebutia, Opuntia. From the above study, we concluded that this farm is one of the diverse regions for succulents and cacti found in Gujarat.
\end{abstract}

Keywords: Cactus, Characters, Spines, Gujarat.

\section{INTRODUCTION}

"Cactus is a succulent plant and the stem is thicker, lack of leaves or leaves modify in to spine or some time both are present and has beautiful flowers in different colour except for blue." The cactus word is coming from Latin word 'Kaktos' means a spiny plant. Most of cactii are native to arid regions of new world.

Cactii are a unique group of plants that are found in its natural environment, in North and South America and South America, maximum seen in Mexico (Slaba,1992).

The major characters in stem are fewer leaves, spines and fleshy wall. The areoles are special characters in the cactus which are protected by spines. Only Pereksiagenus have leaf and in other species leaves modified in to spines. The spines vary in size and colour. It is very important in identification of cactus.

There are seven main types of spines.
1) Hair like spine
2) Needle like spine
3) Awl shaped spine
4) Conical spine
5) Papery spine
6) Feathery spine

\section{7) Hooked spine}

The spines are arranged in such way.

1) Radial spine

2) Central spine

3) Radiate spine

4) Pectinate spine (Slaba,1992)

The cactus is native to Mexico, Morocco, Argentina, Brazil, Peru, Paraguay, Uruguay, Colombia, Arizona, USA etc. in South America and North America continents (Pizzetti,1985).

Countries growing Italy, Turkey, France and yet some part of India.

\section{The Cactus Has Two Groups.}

\section{1) Rain Forest Cactus}

The rain forest cacti store water in their leaves and little different in appearance from their desert dwelling spiny counter parts are known as epiphytic.

Examples: - Epiphyllum and Rhipsalis genera (Bewli,2016).

\section{2) Desert Cactus}

Desert cacti belong to the most cultivated group. They are perennials that emerge in arid zone of American continent. There have been a lot of varieties from Mexico. They can 
International Journal of Research in Advent Technology, Vol.7, No.4, April 2019

E-ISSN: 2321-9637

Available online at www.ijrat.org

be found in their natural habitat in the USA in Arizona, California, and Mexico.

The cactaceae family is divided in to four subfamilies. (Bewli,2016)
1) Pereskioideae (made up of only of genus Pereskia)
2) Opuntioideae
3) Maihuenioideae (made up of genus Maihuenia )
4) Cactoideae (Pizzetti,1985)

\section{EXPERIMENTAL SITE}

We worked on cactus in year 2018 to 2019 for 3 months. We visited Poonam Agriculture farm, Ahmedabad, Gujarat in India. The total area of the farm is 15 acres. The farm environment was dry.

There were 3 greenhouses present in the farm. The area covered by first greenhouse was 20 to 30 square meter and other two greenhouses covered small area in the farm. Two small green houses in the farm were totally covered with the white $50 \%$ shaded film also called as UV stabilizer polythene film. There was a largest green house in the farm and it was totally covered with the white fiber sheet. In this greenhouse mostly the species of cactus were observed. In the greenhouse, different beds were used for plantation. There were 5 beds in front and 2 beds attached to its side.

\section{DOCUMENTATION OF CACTUS}

In the greenhouse mostly 300 species of cactus were observed. Succulents were also present in the greenhouse but as compared to cacti, succulents were less. Out of 300 we studied 14 genus of cactus.

The documentation of cactus was done describing the following characteristics in detail as, Habitat, Plant body, Flowers, and Propagation.

Astrophytum(Lemire):-A. myriostigmais completely spineless and other have long and rigid spine. In this genus, all Astrophytumspecies prefer well drained soil with dry winter rest. They prefer natural alkaline soil. Some growers' added small amount of gypsum to make soil alkaline.

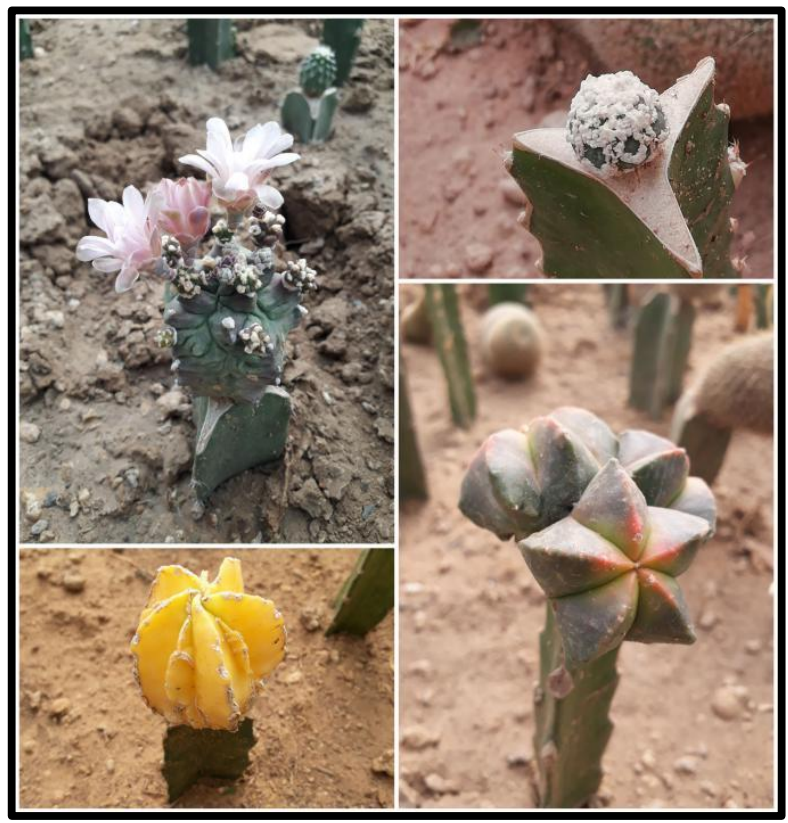

Copiapoa(Britton and Rose):-1) Spherical shaped cactus that produces offsets from low cushions of plant. 2) The second contains large plants that do not offset easily and become elongated with age.

They have variety of coloured spines.

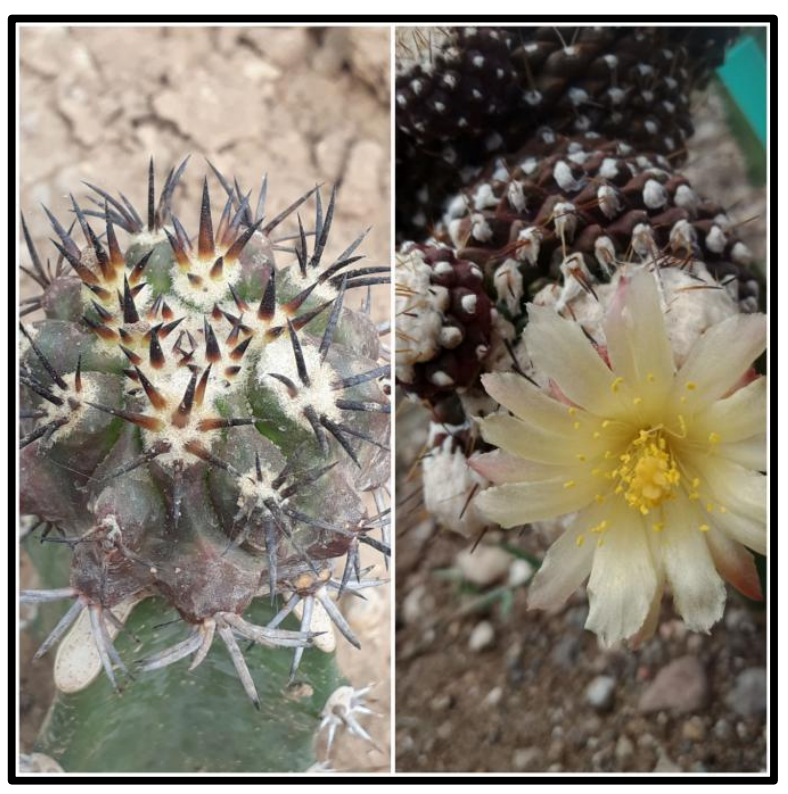

Claistocactus(Lemire) :- It is large group of low to medium height cactus that forms colonies of slender. Spines are compact and bristly and orange to flame coloured flowers rise from side of the mature branches. 
International Journal of Research in Advent Technology, Vol.7, No.4, April 2019

E-ISSN: 2321-9637

Available online at www.ijrat.org

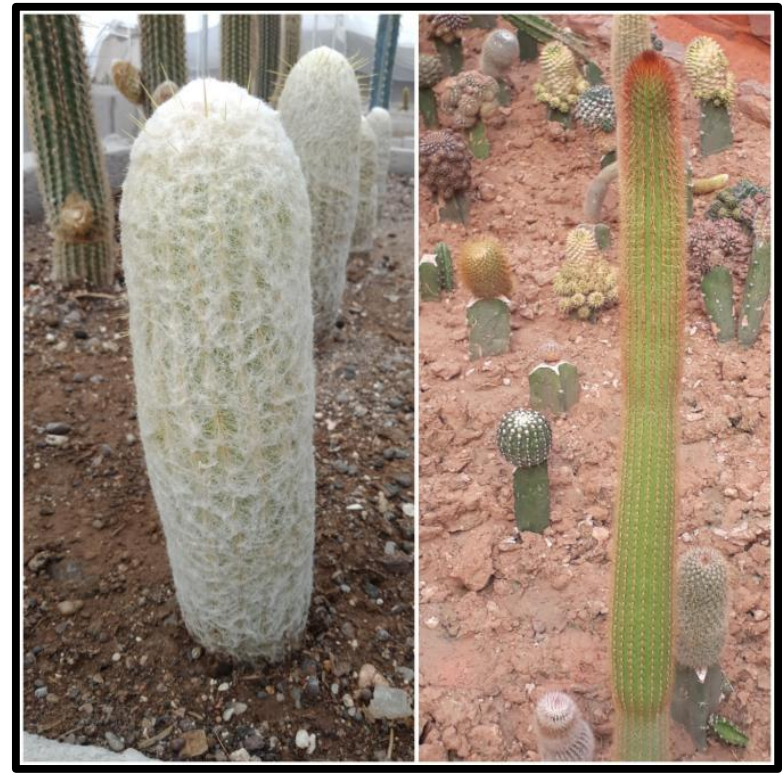

Cereus (Lemire) :- They are tall and columnar in shape, some species grow up to tree-like and their branches have large ribs. Some species are slow growing and smaller shrub. They are hardy in nature and well suited to outdoor. Except for the monstrous form of $C$. Peruvians, the plants generally grow on their own roots.

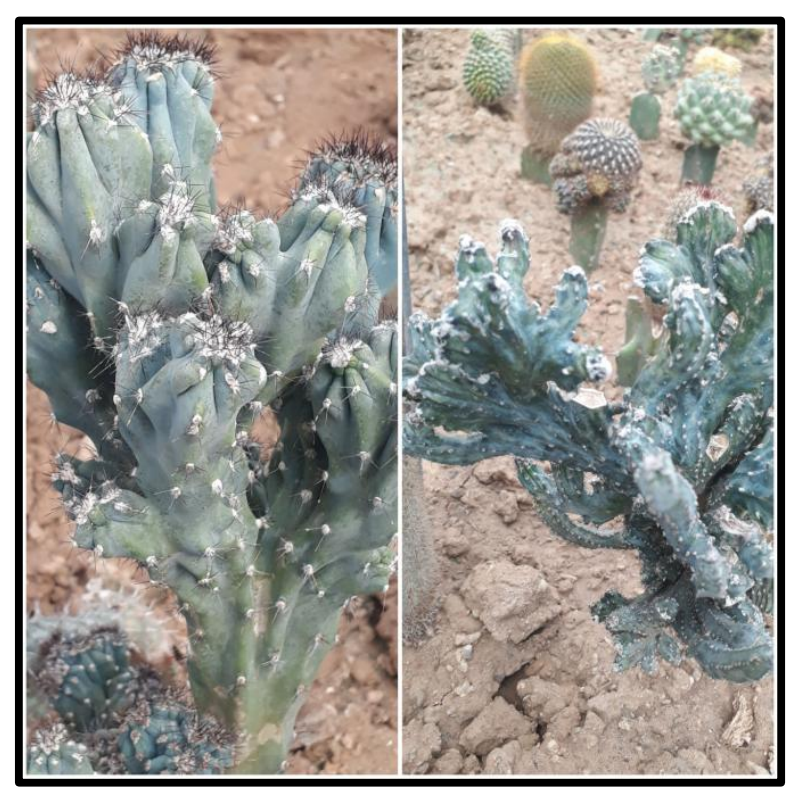

Echinocereus(Engelmann in Wisliz):- All

Echinocereusspecies are short and cylindrical in shape.

Flowers are large and attractive. They are easily propagated. Spines are short and 'pectinate' in shape.

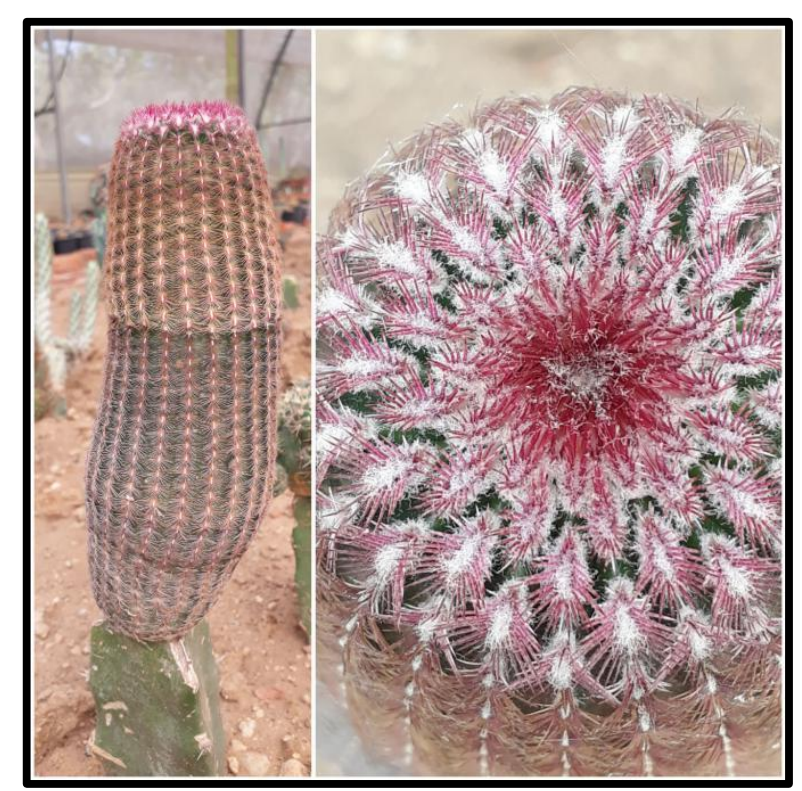

Echinopsis(Zuccarini) :- The Echinopsis genus was initially classified as combination of Echinopsis, Trichocereus, Lobiviaand Psudolobivia, now it has been accepted that all deferring groups should be separate. The plants are spherical and with age they become elongated. They are hardy plants.

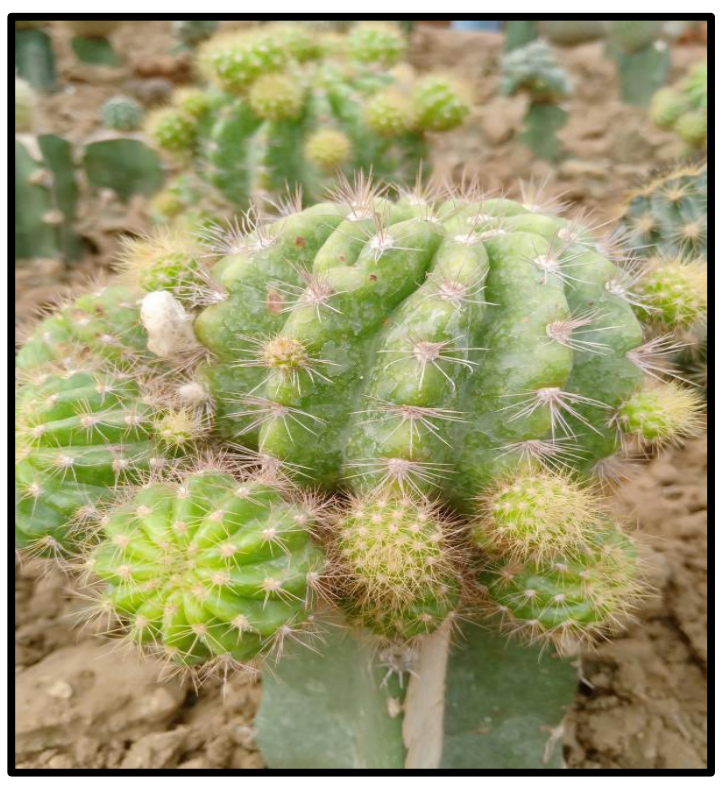

Echinocactus(Britton and Rose):-The member of this genus has heavy spines and small flowers and fruits are profusely woolly and that's the major difference between Echinocactus and Ferocactus. Native to Mexico. 
International Journal of Research in Advent Technology, Vol.7, No.4, April 2019

E-ISSN: 2321-9637

Available online at www.ijrat.org

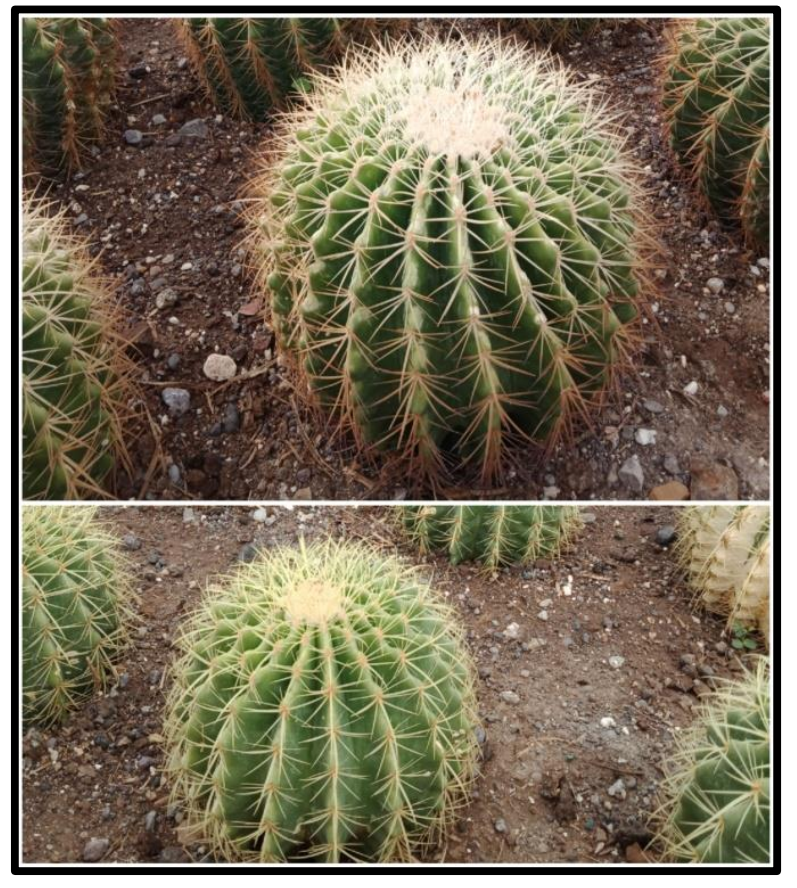

Espostoa (Britton and Rose):- It is native to Peru and Southern Ecuador. It is a taller shrub and stem is branched from the side. The spines are hair like and grow in columnar shape. It is a slow growing plant.

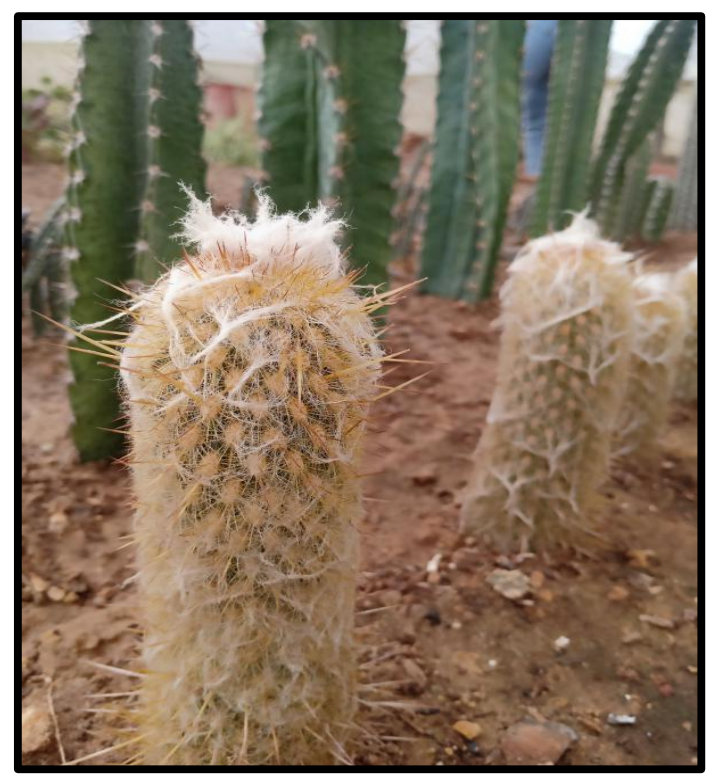

Ferocactus(Britton and Rose):- The word Ferocactuscomes from Latin word 'ferox' means fierce. It is also known as barrel cactus. It is found in desert area and dry environment. It can grow up to 10 feet. The stem is normally strong and it has heavy spines with thick hooked central spines.

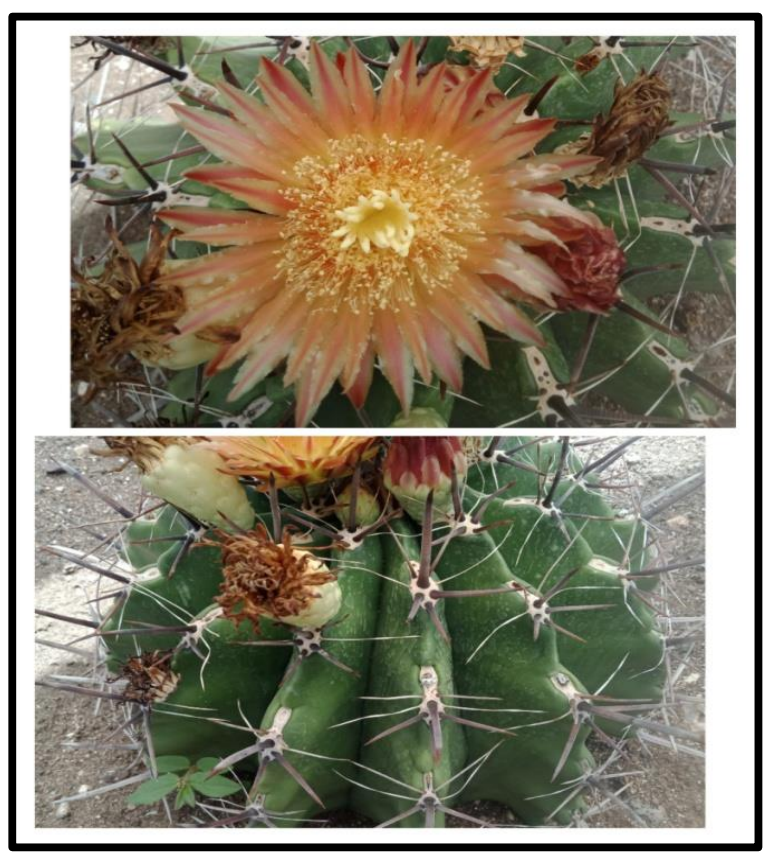

Gymnocalycium (Pfeiff. ex Mittler):- It was mentioned as separate genus in 1845. It is hardy plant and small to medium size, spherical shaped. Japan produced variegated plants under mutation. They have lack chlorophyll which have grafted to survive.

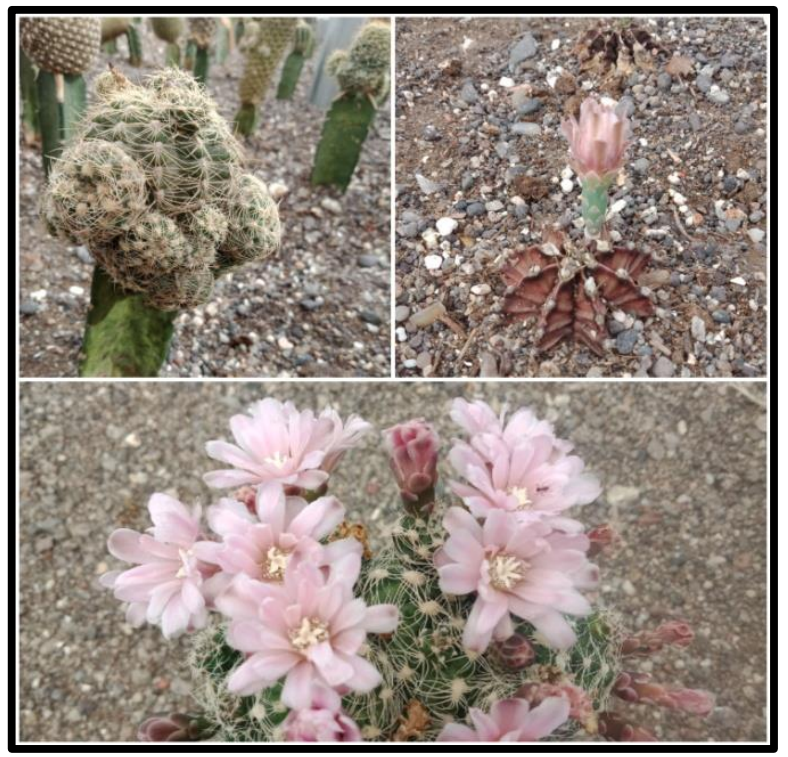

Mammillaria (Haworth.):-In the Mammillaria genus total 350 species were already identified and it is one of the largest genus in the cactaceae family.

The word Mammillaria comes from the Latin word mamma- 'mamilla' means a nipple shaped organ. The equal character of all Mammillaria species is arrangement of tubercles in spiral which replace the ribs that are found in the other cactus. 
International Journal of Research in Advent Technology, Vol.7, No.4, April 2019

E-ISSN: 2321-9637

Available online at $w w w . i j r a t . o r g$

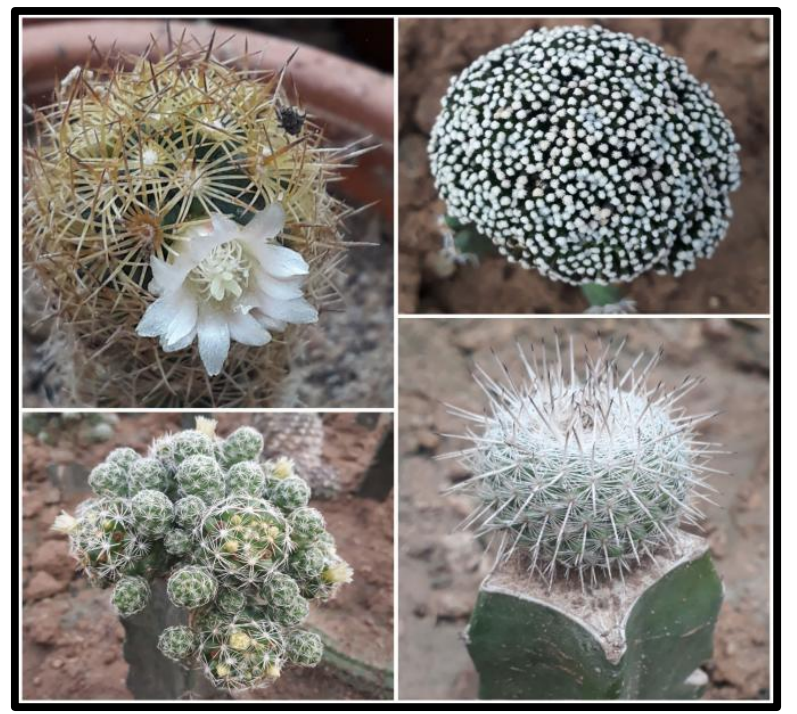

Notocactus(K. Schumann):- It is spherical to oval in shape and spines are attractive, large yellow glossy flowers. They need good coarse soil with full sunlight. Some species of Notocactuswill increase in their size and become oval with age, they normally grow in their own roots.

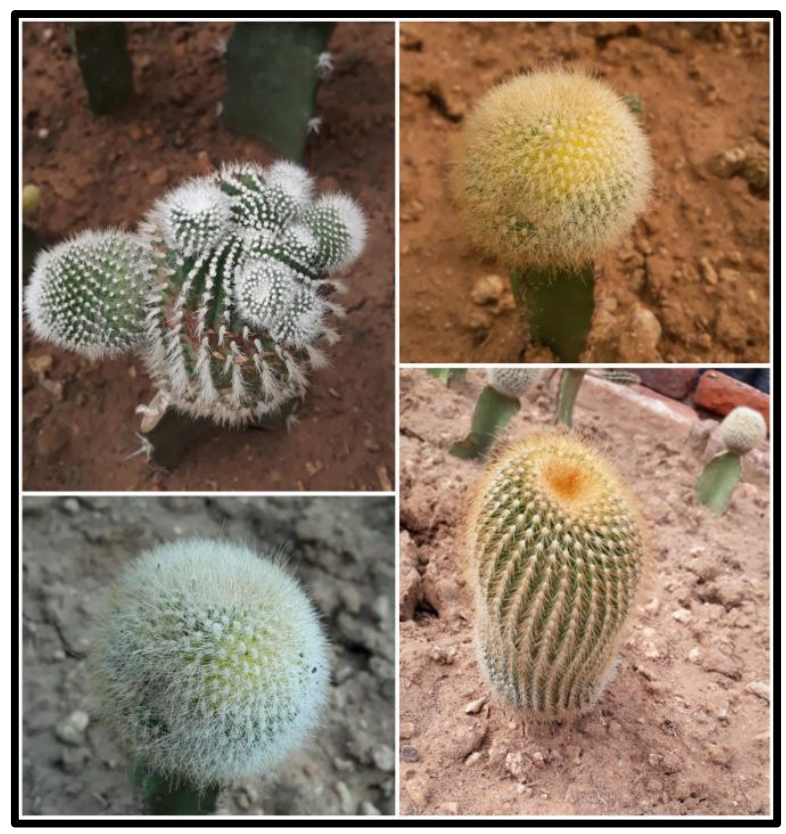

Opuntia (Tourneft):- In the cactaceae family, it is the second largest genus. Large variations are seen in the species of opuntia from large tree like to small shrub, it is hardy plant and suitable for outdoor. In some species of opuntias, their fruits are attractive and edible. It is not necessary to graft because they grow well in their own roots

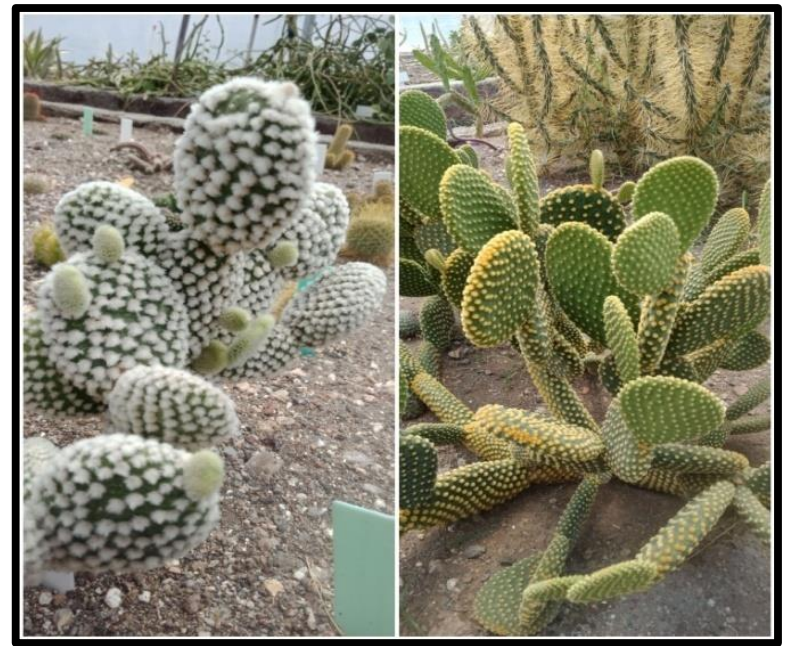

Sulcorebutia (Backeberg):- It is spherical shaped cactus with thick spines. Areoles are elongated and large tap root. The offsets are freely developed. It can be larger plant then Rebutia. They need coarse soil with dry winter rest. They can grow well in their own roots.

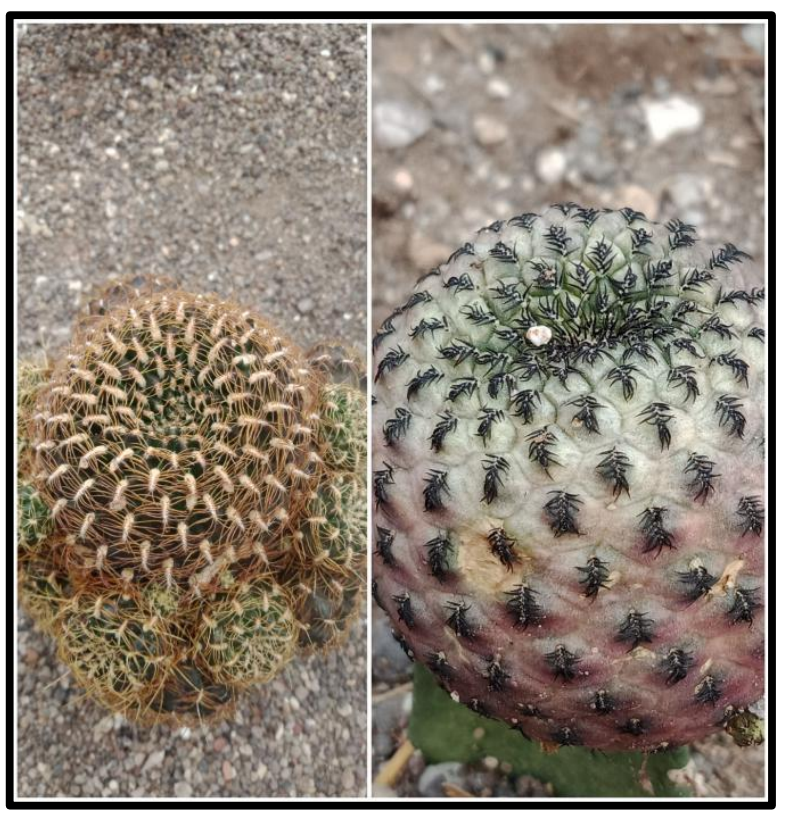

\section{CONCLUSION}

There are total species of 1500 to 1800 species and 178 genera of cactus in the world. Out of these, we saw 300 species of cactus in the field and studied 14 genusAstrophytum, Copiapoa, Claistocactus, Espostoa, Echinocactus, Echinocereus, Echinopsis, Cereus, Ferocactus, Gymnocalycium, Mammillaria, Notocactus, Sulcorebutia, Opuntia. Out of these, 4 rare species were observed. Peniocereus maculatus, Astrophyrummyriostigma var. Fukuryu variegated, Astrophytummyriostigmakohyo, Astrophytummyriostigma 
International Journal of Research in Advent Technology, Vol.7, No.4, April 2019

E-ISSN: 2321-9637

Available online at www.ijrat.org

var. Kiko.From the above study, we conclude that this farm is one of the diverse regions for succulents and cacti found in Gujarat. Due to industrialization, there is a loss of succulents, hence, it is very important to conserve them.

\section{ACKNOWLEDGMENTS}

We would like to thank to Dr. Vashram P. Boda for providing us guidance and research field. We would like to thank Department of Botany, Gujarat University for providing us the facilities for research work.

\section{REFERENCES}

[1] Bewli C. S. "Cacti Culture Prickles of Pride". Fingerprint Life, pages 13-24, 37-66, 2016.

[2] Pizzetti M. "The Macdonald Encyclopedia of Cacti." A Member of Maxwell Macmillan Pergamon Publishing Corporation, pages pages 11-60, 1985.

[3] Slaba R. 'The Illustrated Guide to Cacti". Chancellor press, pages 6-22, 1992. 